\title{
Pişirme ve Yiyecek Hazırlama Becerileri Ölçeğinin Türkçe Geçerlik ve Güvenirliğinin İncelenmesi
}

\section{Evaluation of Validity and Reliability of the Turkish Form of Cooking Skills and Food Skills Measure}

\section{Gizem Keleş ${ }^{1}$, Mehtap Akçil Ok}

Geliş tarihi/Received: 15.10 .2020 • Kabul tarihi/Accepted: 26.02.2021

\section{ÖZET}

Amaç: Bu çalışmada; orijinali İngilizce olan “Pişirme ve Yiyecek Hazırlama Becerileri (PB ve YHB)” ölçeğinin Türkçe geçerlik ve güvenirliğini değerlendirerek Türkçeye uyarlanmasının yapılması amaçlanmıştır.

Bireyler ve Yöntem: Çalışmaya 150 kadın, 150 erkek birey olmak üzere toplamda 300 kişi katılmıştır. Ölçek önce İngilizce’den Türkçe’ye daha sonra Türkçe'den İngilizce’ye çevrilip, orijinal ölçek ile karşılaştırılarak Türkçe uyarlaması tamamlanmıştır. PB ve YHB alt boyutundan oluşan bu ölçek toplamda 33 soru içermektedir.

Bulgular: Çalışmaya katılan bireylerin yaş ortalaması $36.4 \pm 13.16$ yll olup, \%49.3’ü lisans ve \%5’i ise lisansüstü mezunudur. Çalışmada, Bartlett Küresellik Testi sonucuna göre maddeler arasında faktör analizi yapılabilecek yeterli düzeyde ilişkili olduğu belirlenmiştir ( $\chi^{2}=5928$; $\left.p<0.0001\right)$. Açıklayıcı faktör analizi ile PB ve YHB ölçeğinin, orijinalinde belirtildiği şekilde iki faktör (boyut) altında toplandığı sonucuna varılmıştır. Doğrulayıcı faktör analizi sonuçlarına göre, PB ve YHB ölçeğinin Türkçeye uyarlanmasının kabul edilebilir olduğu saptanmıştır. Ölçeğin, Cronbach’s Alfa İç Tutarlılık Katsayısı ( $\alpha=0.954)$ yüksek düzeyde bulunmuştur. Test-tekrar test güvenirlik analizleri sonuçlarına göre ölçek toplam puanının hem öncesi hem de sonrası arasındaki sınıf içi korelasyon katsayısı (ICCC) 0.73 olarak bulunmuştur.

Sonuç: Bu çalışmada, PB ve YHB ölçeğinin Türkçe geçerlik ve güvenirliğinin değerlendirilmesi sonucunda Cronbach’s Alfa’ya göre çok yüksek derecede güvenilir olduğu saptanmıştır.

Anahtar kelimeler: Pişirme becerileri, yiyecek hazırlama becerileri, geçerlik, güvenirlik, ölçek adaptasyonu

\section{ABSTRACT}

Aim: In this study; it was aimed to adapt the "Cooking Skills and Food Skills (CS and FS)" measure, originally in English, to Turkish by evaluating its Turkish version’s validity and reliability.

Subjects and Method: A total of 300 people, 150 women and 150 men, participated in the study. The measure was first translated from English to Turkish and then Turkish version was back-translated to English. Turkish adaptation of the measure was completed by comparing the back-translation to the original. This measure, which consists of CS and FS subdimensions, includes 33 items in total.

1. İletişim/Correspondence: Başkent Üniversitesi Sağlık Bilimleri Fakültesi Beslenme ve Diyetetik Bölümü, Ankara, Türkiye

E-posta: dytgizemkeles@gmail.com • ๑ https://orcid.org/0000-0001-9916-3456
2. Başkent Ũniversitesi Sağlık Bilimleri Fakültesi Beslenme ve Diyetetik Bölümü, Ankara, Türkiye • ๑ https://orcid.org/0000-0002-1793-8092 
Results: The average age of the participants attended to the study is $36.4 \pm 13.16$ years: $49.3 \%$ are undergraduate and $5 \%$ graduate. In the study, according to the Bartlett Test of Sphericity, it was determined that there was a sufficient level of correlation between the items to perform a factor analysis $\left(\chi^{2}=5928\right.$; $\left.p<0.0001\right)$. With the Explanatory Factor Analysis, it was concluded that the CS and FS measure was gathered under two factors (dimensions) as stated in the original. According to the Confirmatory Factor Analysis results, it was found that the adaptation of the CS and FS measure to Turkish was acceptable. The Cronbach's Alpha Internal Consistency Coefficient $(\alpha=0.954)$ of the measure was found to be high. According to the results of test-retest reliability analysis, for the measure's total score; the intra class correlation coefficient (ICCC) between both before and after was found to be 0.73 .

Conclusion: In this study, as a result of the evaluation of the Turkish validity and reliability of the CS and FS measure, it was found that measure is very reliable according to Cronbach's Alpha.

Keywords: Cooking skills, food skills, validity, reliability, measure adaptation

\section{Gíriş}

Besinlerin hazırlanması ve pişirilmesi için uygulanan işlemler; vücut ağırlık durumunu, diyet kalitesini ve yiyecek hazırlama sırasında oluşan karsinojen maddelerin hastalık oluşturma riskini de etkilemektedir (1). Pişirme yöntemlerine bağlı olarak oluşan; heterosiklik aminler (HA), polisiklik aromatik hidrokarbonlar (PAH), N-nitrozo bileşikler, akrilamid, furan, glikasyon son ürünleri (AGE), trans yağ asitleri karsinojenik ve mutajenik olup immün sistem üzerinde olumsuz etkiler göstererek insan sağlığını tehlikeye sokabilmektedir (2). Özellikle obezitenin dünya çapında prevalansı giderek artan önemli sağlık sorunlarından biri olması nedeniyle pişirme ve yiyecek hazırlama becerilerini arttırma önem kazanmaktadır. Bu beceriler, obeziteyi önleme ve azaltma stratejilerine giderek daha fazla dâhil edilmektedir $(3,4)$.

Yemek pişirme becerisi; doğrama, karıştırma, ısıtma vb. içeren "yemek hazırlamada kullanılan mekanik veya fiziksel beceriler kümesi” olarak tanımlanmıştır ve aynı zamanda pişirildiğinde besindeki değişikliklerle ilgili kavramsal ve algısal becerileri de kapsamaktadır. Pişirme becerilerinin yanı sıra, yemek hazırlama sürecinin daha geniş bileşenlerini tanımak ve ölçmek için yiyecek hazırlama becerisi popülerlik kazanmıştır. Yiyecek hazırlama becerisi; mevcut kaynakları kullanarak besinleri satın alma, hazırlama ve pişirme, onları tüketen kişilerin yaşlarına ve ihtiyaçlarına uygun olarak iyi dengelenmiş, lezzetli yemekler üretme yeteneği olarak tanımlanmıştır $(3,5)$. Buna menü planlama, alışveriş, bütçeleme, kaynak kullanımı ve etiket okuma da dâhil edilmiştir. $\mathrm{Bu}$ beceriler ev ortamında yemek hazırlamak için çok önemlidir (6).

Yoğun programlar, günlük streslere neden olan faktörler, hazır besine yönelim, pişirme bilgisi ve güven eksikliği evde yemek pişirme ve yiyecek hazırlama becerilerinin azalmasına neden olmaktadır (7). Bu faktörlere bağlı olarak dışarıda hazırlanan yemekler daha çok tercih edilmektedir. Yapılan çalışmalarda, evde hazırlanan ve tüketilen yemeklerin sağlık açısından daha yararlı olduğu ve diyet kalitesini olumlu etkilediği saptanmıştır (8-10). ABD-Ulusal Beslenme ve Sağlık Araştırması (National Health and Nutrition Examination Survey-NHANES) 2007-2010 analizlerinin özetlendiği bir çalışmada, evde hazırlanan yemeklerin daha az enerji alımı, şeker ve yağ tüketimi ile ilişkili olduğunu göstermiştir (8).

Pişirme ve yiyecek hazırlama becerilerini etkileyen faktörlere bakıldığı zaman; yaş, cinsiyet, sosyoekonomik durum, etiket okuma, besin güvenliği ve besin çeşitliliği hakkında bilgi, tercihler, kolaylık ve sosyal çevre yer almaktadır. Eğitim ve sosyoekonomik düzeyin düşük olması kötü beslenme ile ilişkili temel faktörlerdir. Bu faktörler, yetersiz besin erişimi, besin ve beslenme okuryazarlığında eksiklik 
nedeniyle pişirme ve yiyecek hazırlama becerilerini olumsuz yönde etkilemektedir $(11,12)$.

Beslenme bilgisi, sağlıklı bir diyetin nasıl oluşturulacağına dair bilgi sağlar. $\mathrm{Bu}$ bilgiyi uygulamaya dönüştürmek için pişirme becerisi, planlama ve satın alma becerileri gibi diğer yiyecek hazırlama becerileri de gereklidir $(12,13)$.

Bu çalışmada; Lavalle et al. (6) tarafından 2017 yılında geliştirilen “Cooking Skills and Food Skills” ölçeğinin Türkçe geçerlik ve güvenirliğini değerlendirerek Türkçe uyarlamasının yapılması amaçlanmıştır.

\section{BİREYLER VE YÖNTEM}

Bu çalışma; Şubat - Mart 2020 tarihleri arasında Pamukkale Halk Eğitim Merkezi ve Akşam Sanat Okulu'nda kursa katılan 18-64 yaş arası gönüllü, 150 kadın, 150 erkek birey olmak üzere 300 bireyle yürütülmüştür. Pamukkale Halk Eğitim Merkezi ve Akşam Sanat Okulu'nda yiyecek içecek hazırlama kursuna katılanlar ile halk oyunları, spor ve dil gibi beslenme ile ilgili olmayan diğer kurslardaki bireyler çalışmaya dâhil edilmiştir. Bu çalışma için, Başkent Üniversitesi Tıp ve Sağlık Bilimleri Araştırma Kurulu tarafindan KA19/431 numaralı araştırma projesi olarak 30/09/2020 tarih ve 20/102 sayılı kararı ile "Etik Kurul Onayı” alınmıştır.

Pişirme ve Yiyecek Hazırlama Becerileri ölçeğinin geçerlik ve güvenirlik çalışması için iletişimden sorumlu yazar Fiona Lavalle ile e-posta yoluyla iletişim kurulmuş ve ölçeğin uyarlanabileceğine ilişkin gerekli izinler alınmıştır.

\section{Pişirme ve Yiyecek Hazırlama Becerileri Ölçeği}

Pişirme ve Yiyecek Hazırlama Becerileri (PB ve YHB) ölçeği Lavelle et al. (6) tarafindan geliştirilen, iki alt boyutu olan 33 maddeden oluşan bir ölçektir. Pişirme becerileri alt boyutu 14 maddeden ve yiyecek hazırlama becerileri alt boyutu ise 19 maddeden oluşmaktadır. Alt boyutları güvenirlik katsayılarına bakıldığında; cooking skills (pişirme becerileri) güvenirlik ölçeği için iç tutarlılık güvenirliği tüm kohortlarda 0.78 ile 0.93 arasında olduğu, yiyecek hazırlama becerileri (food skills) güvenirlik ölçeğinin ise Cronbach's a katsayısının 0.89 ile 0.94 (yüksek derecede güvenilir) arasında olduğu saptanmıştır. PB ve YHB ölçeği obezitenin azalmasına katkıda bulunabilecek bir yöntem olarak geliştirilmiştir.

Ölçek, 1'den (çok kötü) 7’ye (çok iyi) kadar değişen ve asla/nadiren seçeneği de olan 8 maddelik Likert bir sistemle puanlandırılmaktadır. Katılımcllardan her beceride ne kadar iyi olduklarının puanlaması istenir ve kullanılan beceriler için 1 ile 7 arasında verilen puanlar toplanır. Asla/nadiren seçeneğini işaretleyen katılımcılar 0 puan almaktadır. Toplam puanın artması pişirme ve yiyecek hazırlama becerisinin arttığı anlamına gelmektedir (6).

\section{Pişirme ve Yiyecek Hazırlama Becerileri Ölçeğinin Geçerlik ve Güvenirlik Analizi}

Pişirme ve Yiyecek Hazırlama Becerileri ölçeğinin dil geçerliliği için önce orijinal dili İngilizce olan ölçeğin Türkçe’ye çevrilmesi Beslenme ve Diyetetik bölümü mezunu İngilizce düzeyi çok iyi olan bir diyetisyen ve iki yeminli tercüman tarafindan gerçekleştirilmiştir ve çevrilme sürecinde önerilen çeviri-geri çeviri yöntemi kullanılmıştır (14). Ölçeğin dil ve anlam açısından anlaşılabilirliğini saptamak amacıyla hem Beslenme ve Diyetetik Bölümü öğretim elemanlarına hem de kursa katılan 20 bireye uygulanan ölçeğe düzeltmeler yapıldıktan sonra son hali verilmiş ve ölçeğin Türkçe uyarlaması tamamlanmıştır.

Ölçeğin geçerlik ve güvenirlik analizlerinin yapılabilmesinin ön koşulu olan örneklem sayısı ve korelasyon yeterliliği analiz edilmiştir. KaiserMeyer-Olkin (KMO) ile örneklem büyüklügünün yeterliliği, Bartlett Küresellik Testi ile de faktör analizinin uygulanabilmesi için maddeler arasında yeterli korelasyonun olup olmadığ incelenmiştir. Kaiser- Meier-Olkin test istatistiği sonuçlarına göre, örneklem büyüklüğünün yeterli olduğu saptanmıştır (KMO=0.93). KMO değerinin 0.50 'den büyük olması, o ölçek verisinin örneklem sayısının yeterli olduğunu göstermektedir (15). Ayrıca Bartlett Küresellik 
Testi sonucuna göre maddeler arasında faktör analizi yapılabilecek yeterli düzeyde ilişkili olduğu saptanmıştır $\left(\chi^{2}=5928 ; \mathrm{p}<0.0001\right)$.

Türkçe’ye uyarlanan PB ve YHB ölçeğinin orijinal ölçeğe olan uyumu "Doğrulayıcı Faktör Analizi (Confirmatory Factor Analysis)" ile değerlendirilmiştir. Uyum (Fit) göstergeleri olan ki-kare $\left(\chi^{2}\right)$ İyi Uyum İndeksi, Düzeltilmiş İyi Uyum İndeksi, Yaklaşık Hatalarm Ortalama Karekökü ve Tahmini Ortalama Karekök Hatası İndeksleri kullanılmıştır. Ölçeğin iki faktörüne ilişkin puanlar ile PB ve YHB ölçeğinin toplam puanları arasındaki korelasyonlar "Pearson Korelasyon Katsayısı” ile hesaplanarak verilmiştir. Bu çalışmada kullanılan Ki-kare ( $\chi^{2}$ ) İyi Uyum İndeksi göz önüne alındığında ölçeğin mükemmel bir uyuma sahip olduğu görülmektedir. Buna ek olarak; Düzeltilmiş İyi Uyum İndeksi (Adjusted Goodness of Fit Index-AGFI) 0.93 bulunmuştur. Bu değerin 0.90’ın üzerinde olması modelin iyi uyumlu olduğunu göstermektedir. Aynı şekilde; Yaklaşık Hataların Ortalama Karekökü (Root Mean Square Residual-RMR) 0.05'in altunda ve Tahmini Ortalama Karekök Hatası (Root Mean Square Error of Approximation-RMSEA)'nın 0.08'den küçük olması modelin iyi uyumunu göstermektedir (16). PB ve YHB ölçeğinin Doğrulayıcı Faktör Analizi uyum indeksi değerleri ve Açıklayıcı Faktör Analizi sonucunda maddelerin yüklendiği faktörler doğrultusunda Türkçe’ye uyarlanmasının kabul edilebilirliğini ve uygulanabilirliğini göstermektedir (15) (Tablo 1 ve Tablo 3).

Ölçeğin maddeleri arasında iç tutarlılığın (güvenirliliğin) hangi düzeyde olduğu, madde toplam korelasyonları ve Cronbach's Alfa İç Tutarlılık Katsayıları ile incelenmiştir. Cronbach's Alfa İç Tutarlılık Katsayısı 0 ile 1 arasında bir

Tablo 1. Doğrulayıcı faktör analizine göre PB ve YHB ölçeğinin uyum istatistikleri

\begin{tabular}{lcc}
\hline Uyum indeksleri & Kriterler & PB-YHB ölçeği \\
\hline$\chi^{2} / s d$ & $3<\chi^{2} / s d<4-5$ & 4.82 \\
AGFI & $\geq 0.90$ & 0.93 \\
RMR & $\leq 0.05$ & 0.042 \\
RMSEA & $0.06-0.08$ & 0.073 \\
\hline
\end{tabular}

değer almaktadır. Bu katsayının 1'e yaklaşması ölçeğin mükemmel derecede güvenilir olduğunu göstermektedir. Son olarak ölçeğinin test-tekrar test güvenirliliğini bulabilmek için 30 kişiye, katılımcıların ölçeği unutmaları beklenerek iki hafta sonra aynı ölçek tekrar uygulanmıştır. Böylece hem ölçeğin genel puanının hem de iki faktörün test-tekrar test güvenirlik katsayısının belirlenmesi sağlanmış ve bunun için de “Sınıf İçi Korelasyon Analizi” yapılmıştır (15).

\section{Verilerin İstatistiksel Değerlendirmesi}

Uyarlaması yapılan ölçeğin yapısal geçerliğinin sınanması Açıklayıcı Faktör Analizi ile ölçeklerin alt boyutlarının orijinal ölçeklerle uyumunun sınanması ise DoğrulayıcıFaktör Analiziile yapılmıştır. Ölçeklerin iç tutarlılıklarının analizi için madde-analizi yapılmış ve güvenirlik katsayıları (Cronbach’s-a) hesaplanmıştır. Gereken tüm bu faktör analizlerinin yapılabilmesi için ölçekte yer alan madde sayısının 5-10 katı kadar sayıda kişiye uygulama yapılmıştır (17). Uygulama yapıldıktan sonra aynı bireylere 2 hafta sonra ölçeğe ait sorular tekrar uygulanmıştır. $\mathrm{Bu}$ sinırlar içinde alınan örnekleme bağlı toplanan veriler için "Sınıf İçi Korelasyon Katsayısı (Intra Class Correlation Coefficient-ICCC)" hesaplanarak istatistiksel olarak değerlendirilmiştir.

Çalışmadan elde edilen verilerin istatistiksel analizleri ve tabloların oluşturulması amacıyla SPSS 21.0 istatistik yazılım programı kullanılarak değerlendirilmiştir. Ölçeğin alt boyutlarının teorik modele uyumunu analiz edebilmek için kullanılan Doğrulayıcı Faktör Analizi yöntemi AMOS Version 21 programından yararlanılarak yapılmıştır. İstatistik analizlerinde önemlilik düzeyi $\mathrm{p}<0.05$ olarak alınmıştır.

\section{BULGULAR}

Çalışmaya, 18-64 yaş arası (yaş ortalaması 36.4 \pm 13.16 yll), 150 kadın (\%50) 150 erkek (\%50) olmak üzere toplam 300 kişi katılmıştır. Bireylerin \%9'u yiyecek içecek hazırlama kurslarına, \%91'i diğer kurslara (spor, halk oyunları, bilgisayar, dil kursları vb.) 
katılmaktadır. Katılımcıların çoğunluğunun evli (\%53.7) ve çocuklu (\%54.3), lisans mezunu (\%49.3) ve aileleriyle (\%87.0) yaşadıkları saptanmıştır. Öğrenci olduğunu beyan edenlerin oranı \%17.4 iken ev hanımı olanların oranı \%16.0, memur olanların oranı \%14.0'dür. Aylık geliri 2021-4000 TL arasında olanların oranı \%47'dir (Tablo 2).

Bu çalışmada 33 maddelik PB ve YHB’nin; orijinalinde belirtildiği şekilde iki faktör (boyut) altında toplandığı saptanmıştır. Her faktörün faktör yükü 0.40'ın üzerinde ve toplam varyans açıklama yüzdesi \%30’un üzerinde olduğundan PB ve YHB ölçeğinin bu faktörlerde değerlendirilebileceği sonucuna varılmıştır (Tablo 3).

Pişirme ve Yiyecek Hazırlama Becerileri Ölçeğinin bütünlüğü için Cronbach’s Alfa İç Tutarlılık Katsayısı 0.954 olarak bulunmuştur. PB ve YHB ölçeğinin Doğrulayıcı Faktör Analizinde onaylanan iki alt boyutu için güvenirlik katsayıları; birinci alt boyut (pişirme becerileri) için 0.90 ve ikinci alt boyut (yiyecek hazırlama becerileri) için 0.92 olarak saptanmıştır. $\mathrm{Bu}$ sonuçlar, her bir alt boyutun iç tutarlılığının olduğunu belirtmektedir. PB ve YHB'nin madde puanları ile toplam puan arasında pozitif ve 0.25 'ten yüksek korelasyon saptanmış olup bu sonuç ölçekten madde çıkarılmamasını göstermektedir. Aynı şekilde her madde ölçekten çıkarılıp tekrar Cronbach's alfa katsayısı hesaplandığında çok farklı değer elde edilmediği için ölçekten madde çıkarılmamasına karar verilmiştir (Tablo 4).

Pişirme ve Yiyecek Hazırlama Becerileri Ölçeğinin tekrar test güvenirliğini bulabilmek için çalışmaya katılan 30 bireye iki hafta sonra aynı ölçek tekrar uygulanmıştır. Zamanın ölçek üzerindeki etkisinin standart olup olmadığını değerlendirmek için yapılmıştır. Böylece hem ölçeğin genel puanının hem de iki faktörün test-tekrar test güvenirlik katsayısının belirlenmesi sağlanmış ve bunun için de "sınıf içi korelasyon katsayısı (ICCC)" hesaplanmıştır. Ölçek toplam puanı için hem öncesi hem de sonrası arasındaki ICCC katsayısı 0.73 olarak bulunmuştur. $\mathrm{Bu}$ değer 0.70 ile 0.84 arasında olduğu için $\mathrm{PB}$ ve
Tablo 2. Bireylerin demografik özellikleri

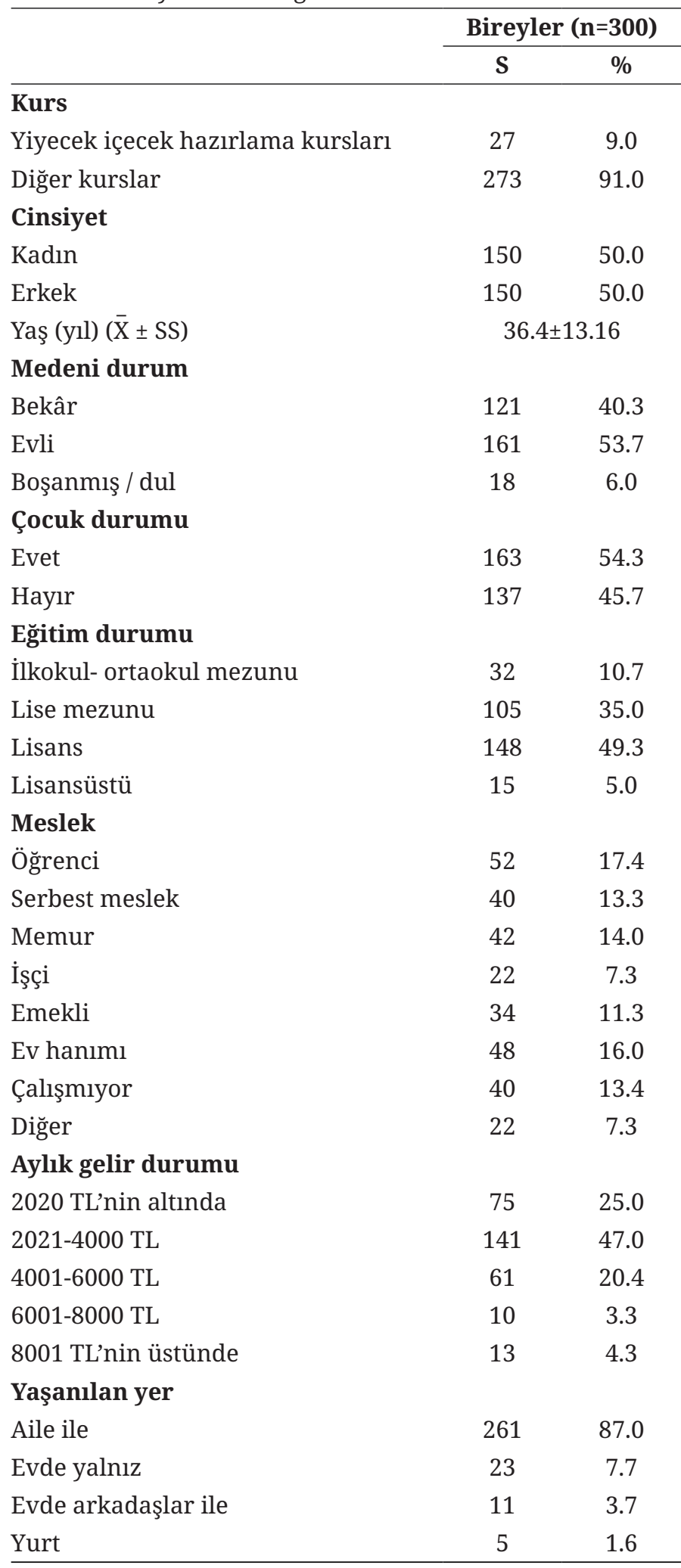

YHB ölçeğinin orta derecede güvenilir olduğunu göstermektedir. 
Tablo 3. PB ve YHB ölçeğinin açıklayıcı faktör analizi sonuçları

\begin{tabular}{|c|c|c|}
\hline Maddeler & $\begin{array}{c}\text { Faktör } 1 \\
\text { Pişirme Becerileri (PB) }\end{array}$ & $\begin{array}{c}\text { Faktör } 2 \\
\text { Yiyecek Hazırlama Becerileri (YHB) }\end{array}$ \\
\hline PB 1 & 0.604 & \\
\hline PB 2 & 0.661 & \\
\hline PB 3 & 0.577 & \\
\hline PB 4 & 0.600 & \\
\hline PB 5 & 0.650 & \\
\hline PB 6 & 0.741 & \\
\hline PB 7 & 0.626 & \\
\hline PB 8 & 0.420 & \\
\hline PB 9 & 0.616 & \\
\hline PB 10 & 0.554 & \\
\hline PB 11 & 0.663 & \\
\hline PB 12 & 0.564 & \\
\hline PB 13 & 0.703 & \\
\hline PB 14 & 0.715 & \\
\hline YHB 1 & & 0.623 \\
\hline YHB 2 & & 0.709 \\
\hline YHB 3 & & 0.711 \\
\hline YHB 4 & & 0.519 \\
\hline YHB 5 & & 0.673 \\
\hline YHB 6 & & 0.626 \\
\hline YHB 7 & & 0.577 \\
\hline YHB 8 & & 0.598 \\
\hline YHB 9 & & 0.540 \\
\hline YHB 10 & & 0.569 \\
\hline YнB 11 & & 0.743 \\
\hline YHB 12 & & 0.766 \\
\hline YHB 13 & & 0.716 \\
\hline YHB 14 & & 0.595 \\
\hline YHB 15 & & 0.751 \\
\hline YHB 16 & & 0.465 \\
\hline YHB 17 & & 0.467 \\
\hline YHB 18 & & 0.392 \\
\hline YHB 19 & & 0.448 \\
\hline Öz değer & 12.661 & 3.015 \\
\hline Varyans Açıllama Yüzdesi & 38.367 & 9.137 \\
\hline
\end{tabular}

Buna ek olarak test ve tekrar testin alt boyutları arasındaki korelasyonlar incelendiğinde; pişirme becerileri 0.85 ve yiyecek hazırlama becerileri 0.89 olduğu saptanmıştır. Bunların sonucunda tüm alt boyutlardaki korelasyonlar pozitif ve istatistiksel açıdan güçlü olarak saptanmıştır ( $\mathrm{p}<0.0001)$.
TARTIŞMA

Araştırmalar, sağlıklı bir diyetin sürdürülebilir olmasının pişirme becerisi ile ilgili olabileceğini göstermektedir (18-20). Fakat insanların yaşam tarzları, eğitim düzeyleri ve hazır yemek öğelerine erişimi, ebeveynlerden çocuğa ve eğitim yoluyla 
Tablo 4. PB ve YHB ölçek maddelerinin güvenirlik analiz sonuçları

\begin{tabular}{|c|c|c|}
\hline Maddeler & Madde-ölçek toplam korelasyonu & $\begin{array}{c}\text { Madde silindiğinde Cronbach's Alfa } \\
\text { Katsayısı }\end{array}$ \\
\hline PB 1 & 0.560 & 0.900 \\
\hline PB 2 & 0.682 & 0.896 \\
\hline РB 3 & 0.594 & 0.899 \\
\hline PB 4 & 0.630 & 0.898 \\
\hline PB 5 & 0.689 & 0.895 \\
\hline PB 6 & 0.743 & 0.893 \\
\hline PB 7 & 0.656 & 0.897 \\
\hline PB 8 & 0.398 & 0.909 \\
\hline PB 9 & 0.615 & 0.898 \\
\hline PB 10 & 0.510 & 0.902 \\
\hline PB 11 & 0.639 & 0.897 \\
\hline PB 12 & 0.568 & 0.900 \\
\hline PB 13 & 0.666 & 0.896 \\
\hline PB 14 & 0.626 & 0.898 \\
\hline YHB 1 & 0.566 & 0.916 \\
\hline YHB 2 & 0.632 & 0.914 \\
\hline YHB 3 & 0.612 & 0.915 \\
\hline YHB 4 & 0.546 & 0.917 \\
\hline YHB 5 & 0.679 & 0.914 \\
\hline YHB 6 & 0.673 & 0.913 \\
\hline YHB 7 & 0.613 & 0.915 \\
\hline YHB 8 & 0.629 & 0.915 \\
\hline YHB 9 & 0.552 & 0.916 \\
\hline YHB 10 & 0.570 & 0.916 \\
\hline YHB 11 & 0.691 & 0.913 \\
\hline YHB 12 & 0.716 & 0.913 \\
\hline YHB 13 & 0.615 & 0.915 \\
\hline YHB 14 & 0.532 & 0.918 \\
\hline YHB 15 & 0.701 & 0.913 \\
\hline YHB 16 & 0.490 & 0.918 \\
\hline YHB 17 & 0.503 & 0.917 \\
\hline YHB 18 & 0.424 & 0.919 \\
\hline YHB 19 & 0.503 & 0.918 \\
\hline PB için Cronbach’s Alfa Katsayısı & \multicolumn{2}{|c|}{0.90} \\
\hline YHB için Cronbach’s Alfa Katsayısı & \multicolumn{2}{|c|}{0.92} \\
\hline
\end{tabular}

pişirme becerilerinin aktarılmasında bir azalmaya yol açmıştır. Kesin olmayan kanıtlara rağmen, evde yiyecek hazırlama ve pişirme becerisi eksikliğinin sağlıklı bir diyete ulaşmada sınırlayıcı bir faktör olduğu düşünülmektedir. Mutfakta beceri kazanma ve geliştirme, daha fazla yiyecek hazırlama öz yeterliliği, yemek pişirme faaliyetlerine artan ilgi ve evde yemek pişirme sıklığının artması sağlıklı beslenme için önemlidir. Bu yüzden yemek pişirme becerileri müdahaleleri çoğalmakta ve bazı ülkeler artık diyet kılavuzlarında evde yemek pişirmekten bahsetmektedir $(18,19)$. 
Obezitenin yaygınlaşması ile tüketime hazır gıdaların kullanımı ve ev dışında yemek yeme sıklığı artmaktadır (6). Bu nedenle bireylerin pişirme ve yiyecek hazırlama becerilerini değerlendirmek ve bu becerilerin kullanımını teşvik etmek büyük önem taşımaktadır. Ev dışında yemek yemenin gittikçe yaygınlaşmasıyla fast-food tüketimine yönelim hızla artmaktadır. Dave et al. (21) yaptığı çalışmada, yemek yapmayı sevmeyen ve hazır gıdaların kolaylığı nedeniyle tercih eden bireylerin fast-food tüketimine yöneldiği ve buna bağlı olarak beden kütle indeksinin arttığı belirlenmiştir. Bu becerilerin erken yaşta kazanılması sağlıklı beslenme alışkanlıklarının sürdürülebilir olmasını etkilemektedir. Yapılan bir çalışmada, çocuk veya genç yaşta pişirme ve yiyecek hazırlama becerilerinin kazanılmasının diyet kalitesi ile pozitif ilişkili olduğu gösterilmiştir (4).

Ülkemizde yaşam tarzının hızla değişmesi sonucunda obezite, halk sağlığını önemli ölçüde tehdit eden ve sıklığı giderek artan bir sorun haline gelmiştir (22). Son yıllarda hızlı yaşam biçiminin artması bireyleri kısa sürede hazırlanan yemeklere yöneltmiştir. Bu durum tüm dünyada olduğu gibi Türkiye'de de etkili olmuş ve ev dışında yemek yeme sıklığı artmıştır (23). $\mathrm{Bu}$ yüzden bireylerin pişirme ve yiyecek hazırlama becerilerini geliştirmesi ve bu becerilerin kullanımını pratikleştirerek evde yemek hazırlama sıklığını artırması, obeziteyi önlemek için bir adım olabilir. Yiyecek hazırlama alışkanlıkları ve becerileri ile sağlıklı beslenme alışkanlıkları arasındaki ilişkiyi inceleyen çalışmalarda, evde yemek hazırlayan bireylerin sebze, salata, meyve tüketimlerinin daha sık, fast-food tüketim sıklıklarının daha az olduğu ve diyet kalitesinin daha yüksek olduğu bulunmuştur $(9,24)$.

Besinlerin hazırlanması, pişirilmesi ve saklanmasındaki temel ilkeler bilinmediği zaman besin ögelerindeki kayıplar da çok fazla olmaktadır (25). Yiyecek hazırlama ve pişirme bir yöntem işidir ve her aşamasında beslenme ilkelerine dikkat etmek gerekir. Besin değeri yüksek yiyecekler üretilebilmesi için besin ögelerinin kimyasal özelliklerini korumak, sindirimini kolaylaştırmak, bozulmasına neden olan mikroorganizmaları ve enzimleri yok ederek sağlık için yararlı hale getirilmelidir (26).

Türk mutfağının pişirme ve yiyecek hazırlama yöntemlerine bakıldığında, sağlıklı uygulamaların yanı sıra sağlıksız bazı uygulamaları da içermektedir. Yemeklerin kızartma ve kavurma yöntemi ile pişirilmesi, yağın yemeğe yakılarak eklenmesi, bazı tatlılar ve hamur işlerinde aşırı şeker ve yağ kullanımı, haşlama ve pişirme sularının dökülmesi hatalı uygulamaların başında gelmektedir (27). Yapılan çalışmalarda da kadınların besinleri hazırlama, pişirme ve çözdürme aşamalarında hatalı uygulamalar yaptıkları belirlenmiştir $(28,29)$. Bu hatalı uygulamalar sonucunda, vücut için gerekli olan besin öğeleri az alınmakta veya hiç alınmamaktadır. $\mathrm{Bu}$ yüzden insanlar yetersiz ve dengesiz beslenme sorunu ile karşı karşıya kalabilmektedir (25).

Bu sonuçlardan yola çıkarak; farklı araştırma türlerine uygun olan, bireylerin pişirme ve yiyecek hazırlama becerisini ölçmek amacıyla Lavalle et al. (6) obezitenin azalmasına katkıda bulunabilecek bir yöntem olarak PB ve YHB ölçeğini geliştirmiştir. Bu çalışmada ölçekte saptanan değerler PB ve YHB ölçeğinin Türkçe’ye uyarlanmasının kabul edilebilirliğini ve uygulanabilirliğini göstermektedir. Çalışmada, PB ve YHB ölçeğinin güvenirlik katsayısı (Cronbach's Alfa) 0.954, PB ve YHB ölçeğinin Doğrulayıcı Faktör Analizinde onaylanan iki alt boyutu için güvenirlik katsayıları ise; birinci alt boyut (pişirme becerileri) için 0.90 ve ikinci alt boyut (yiyecek hazırlama becerileri) için 0.92 olarak saptanmıştır (Tablo 4). Test-tekrar test sonuçlarına göre ölçeğin alt boyutları arasındaki korelasyonları incelendiğinde; PB 0.85 ve YHB 0.89 olduğu belirlenmiştir. Bunların sonucunda, tüm alt boyutlardaki korelasyonlar pozitif ve istatistiksel açıdan güçlü olarak saptanmıştır ( $\mathrm{p}<0.0001$, tabloda gösterilmemiştir). Lavalle et al. (6) yaptığı çalışmaya benzer olarak, PB ve YHB ölçeğinin güvenirlik katsayısı (Cronbach's Alfa) 0.70’ten büyük olduğu ve klinik olmayan ölçekler için yeterli olduğu bulunmuştur. Pişirme Becerileri iç tutarlılık güvenirliği tüm kohortlarda 0.78 ile 0.93 arasında olduğu, Yiyecek Hazırlama Becerileri ise Cronbach's Alfa katsayısının 
0.89 ile 0.94 (yüksek derecede güvenilir) arasında olduğu saptanmıştır ve zaman içinde tutarlılığa sahip olduğu görülmüştür.

Sonuç olarak, bu çalışmada PB ve YHB ölçeğinin geçerlik ve güvenirlik çalışması yapılmış ve Cronbach's Alfa'ya göre çok yüksek derecede güvenilir olduğu saptanmıştır. Aynı zamanda bu ölçek, bireylerin pişirme ve yiyecek hazırlama becerileri düzeyini ölçerek hangi yöntemlerde eksiklerin olduğunun bulunmasında yardımcı olabilir. Buna göre; programlar düzenlenip bireylerin bilinçlendirilmesi sağlanabilir. $\mathrm{Bu}$ becerilerin gelişmesi, evde yemek pişirme sıklıklarının artmasında, daha sağlıklı besinler tüketilmesinde ve obezitenin önüne geçilmesinde bir ışık olabilir. Bu yüzden, gelecekte bu ölçeğin kullanıldığı çalışmaların yapılmasına ihtiyaç duyulmaktadır.

Çıkar çatışması - Conflict of interest: Yazarlar çıkar çatışması olmadığını beyan ederler. - The authors declare that they have no conflict of interest.

Etik Kurul Onayı: Bu çalışma için, Başkent Üniversitesi Tıp ve Sağllk Bilimleri Araştırma Kurulu tarafindan KA19/431 numaralı araştırma projesi olarak 30/09/2020 tarih ve 20/102 sayılı kararı ile "Etik Kurul Onayı" alınmıştır.

\section{KAYNAKLAR}

1. Raber M, Chandra J, Upadhyaya M. An evidence-based conceptual framework of healthy cooking. Prev Med Rep. 2016;4:23-8.

2. Güneş F. Pişirme yöntemleri, oluşan kimyasal maddeler ve immün sistem. Turkiye Klinikleri J Nutr Diet-Special Topics. 2016;2(2):106-12.

3. McGowan L,PotG,Stephen A, LavalleF,Spence M, Raats M, et al. The influence of socio-demographic, psychological and knowledge-related variables alongside perceived cooking and food skills abilities in the prediction of diet quality in adults: A nationally representative crosssectional study. IJBNPA. 2016;13:111.

4. Lavelle F, Spence M, Hollywood L, McGowan L, Surgenor D, McCloat A, et al. Learning cooking skills at different ages: A cross-sectional study. IJBNPA. 2016;13:119.

5. McGowan L, Carahe M, Raats M, Lavalle F, Hollywood L, McDowell D, et al. Domestic cooking and food skills: A review. Crit Rev Food Sci Nutr. 2017;57:2412-31.

6. Lavelle F, Mcgowan L, Hollywood L, Surgenor D, McCloat
A, Mooney E, et al. The development and validation of measures to assess cooking skills and food skills. IJBNPA. 2017;14:118.

7. Herbert C, Flego A, Gibbs L, Waters E, Swinburn B, Reynolds J, et al. Wider impacts of a 10-week community cooking skills program- Jamie's Ministry of Food, Australia. BMC Public Health. 2014;14:1161.

8. Tiwari A, Aggarwal A, Tang W, Drewnowski A. Cooking at home: A strategy to comply with U.S. Dietary Guidelines at no extra cost. Am J Prev Med. 2017;52(5):616-24.

9. Monsivais P, Aggarwal A, Drewnowski A. Time spent on home food preparation and indicators of healthy eating. Am J Prev Med. 2014;47(6):796-802.

10. Fulkerson J, Farbakhsh K, Lytle L, Hearst M, Dengel $\mathrm{D}$, Pasch $\mathrm{K}$, et al. Away-from-home family dinner sources and associations with weight status, body composition and related biomarkers of chronic disease among adolescents and their parents. J Am Diet Assoc. 2011;111(12):1892-7.

11. Garcia A, Reardon R, McDonald M, Garcia E. Community interventions to improve cooking skills and their effects on confidence and eating behaviour. Curr Nutr Rep. 2016;5:315-22.

12. Ballam R, Balmer R, Caraher M, Carroll K, Henderson G, Holmes C, et al. Food skills: Definitions, influences and relationship with health. Safe Food [Internet] 2014 [cited 2021 Jan 2] 11-32 p. Available from: https:// www.safefood.net/getattachment/48acd55e-0865-452f96ca-7a959120ab18/Food-Skills-Edited-Final-Report. pdf?lang=en-IE

13. Ternier S. Understanding and measuring cooking skills and knowledge as factors influencing convenience food purchases and consumption. SURG. 2010;3(2):69-76.

14. Köse G, Tayfur M, Birincioğlu İ, Dönmez A. Yeme Farkındalığı Ölçeği’ni Türkçeye uyarlama çalışması. JCBPR. 2016;3:125-34.

15. Alpar R. Çok değişkenli istatistiksel yöntemler. 4. baskı. Ankara: Detay Yayıncılık; 2013. s. 294-349.

16. Şimşek Ö. Yapısal eşitlik modellemesine giriş. Ankara: Ekinoks; 2007. s. 88-89.

17. Menekli T, Fadıloğlu Ç. Beslenme Değişim Süreçleri Ölçeğinin geçerlik ve güvenirliği. SBÜHD. 2012;1-21.

18. Condrasky M, Williams J, Catalano P, Griffin S. Development of psychosocial scales for evaluating the impact of a culinary nutrition education program on cooking and healthful eating. J Nutr Educ Behav. 2011;43(6):511-6.

19. Astbury C, Penney T, Adams J. Comparison of individuals with low versus high consumption of home-prepared food in a group with universally high dietary quality: A cross-sectional analysis of the UK National Diet \& Nutrition Survey (2008-2016). IJBNPA. 2019;16:9. 
20. Bernardo G, Jomori M, Fernandes A, Colussi C, Condrasky M, Proença R. Positive impact of a cooking skills intervention among Brazilian university students: Six months follow-up of a randomized controlled trial. Appetite, 2018; 130: 247-255.

21. Dave J, An L, Jeffery R, Ahluwalia J. Relationship of attitudes toward fast food and frequency of fast-food intake in adults. Obesity. 2009;17:6.

22. TEMD, Obezite Tanı ve Tedavi Kılavuzu [Internet] Ankara, 2019. Erişim: https://temd.org.tr/admin/ uploads/tbl_kilavuz/20190506163904-2019tbl_ kilavuz5ccdcb9e5d.pdf Erişim tarihi: 21 Ocak 2021.

23. Altaş A, Uzun F. Üniversite öğrencilerinin yemek tercihleri: Aksaray Üniversitesi öğrencileri üzerinde bir çalışma. IJHS. 2017;14(4):4435-52.

24. Larson N, Perry C, Story M, Sztainer D. Food preparation by young adults is associated with better diet quality. J Am Diet Assoc. 2006;106:2001-7.
25. Derin D, Işık N, Erdem N. Konya il merkezinde yaşayan kadınların yiyecek hazırlama, pişirme ve saklama uygulamaları üzerine bir araştırma. SUSBED. 2016;35:87-101.

26. Koçak H. Yiyecek Hazırlama ve Pişirme UygulamalarıAmasya Örneği [Bilim Uzmanlığı Tezi]. Ankara Üniversitesi Fen Bilimleri Enstitüsü, Ankara; 2005.

27. Büyüktuncer Z, Yücecan Z. Türk mutfağının beslenme ve sağlık açısından değerlendirilmesi. Bes Diy Derg. 2009;37(1-2):93-100.

28. Topçu A, Köksal E, Bilgili N. 15-49 yaş grubu ev hanımlarının besin hazırlama, pişirme ve saklama yöntemleri konusunda bigi, tutum ve davranışlarına yönelik bir araştırma. Türk Hij Den Biyol Derg. 2003;60(3):77-86.

29. Ateş M, Ballar E, Pekcan G. Sosyo-ekonomikyönden farklı semtlerde yaşayan ev kadınlarının besin hazırlama, pişirme ve saklama yöntemlerinin saptanması. Bes Diy Derg. 1986;15:71-83. 